\title{
Planning of Fixed-Route Fixed-Schedule Feeder Service to Bus Stops in Rural India
}

\author{
Sudhanshu Sekhar Das ${ }^{1}$; Bhargab Maitra ${ }^{2}$; and Manfred Boltze ${ }^{3}$
}

\begin{abstract}
Rural feeder service between villages and bus stops is largely a missing component in developing countries such as India. Traditionally, planning of rural feeder service has been carried out without due consideration to indirect costs associated with hard factors (e.g., walking distance and waiting time) and soft factors (e.g., crowding inside vehicles) of the service. A case study is presented for the planning of rural feeder service with due consideration to direct and indirect costs to users and operational viability of the service. Direct and indirect costs to users are expressed in terms of a comprehensive measure called generalized cost (GC). GC is developed on the basis of the willingness to pay (WTP) of rural commuters with respect to various attributes of rural feeder service. The work demonstrates the effect of catchment characteristics (i.e., number of villages, size of villages, and spatial separation represented by road network connecting villages to bus stop) on feeder service attributes (i.e., type of vehicle, route, headway of service and fare). It is also shown that planning of feeder service could be instrumental in bringing benefits to rural communities. The results presented in the paper are case specific, but the methodology can be applied to the planning of feeder services in other rural regions. DOI: 10.1061/(ASCE)TE.1943-5436.0000419. (C) 2012 American Society of Civil Engineers.
\end{abstract}

CE Database subject headings: Rural areas; Buses; Public transportation; India; Routing.

Author keywords: Rural feeder service; Generalized cost; Measure of effectiveness; Feeder vehicles; Feeder routes.

\section{Introduction}

Over several decades, the lack of roads in rural areas has been a major bottleneck for accelerating the economic growth of developing countries such as India. In recent years, road connectivity in rural India has improved significantly with the construction of roads under a rural road development program (Sikdar 2002). Rural population, which constitutes about $70 \%$ of the country's population, predominantly includes economically backward households with negligible vehicle ownership. Therefore, not only rural roads but also the public transportation system is an important consideration in the context of India's economic development. All major or higher-order roads in rural India are generally served by the bus system, but feeder service between villages and bus stops is largely a missing component. Traditionally, walking and bicycles have been used by rural commuters for accessing bus stops. With the development of rural roads, it is now possible to operate a feeder service for the transfer of passengers between villages and bus stops. Accordingly, the planning of rural feeder service has become a necessary task.

Several studies have been reported in the literature on routing, scheduling, and design of feeder service in urban areas (Wirasinghe

${ }^{1}$ Principal, RSR Rungta College of Engineering and Technology, Bhilai, Chattisgarh, India. E-mail: ssdas8@gmail.com

${ }^{2}$ Associate Professor, Dept. of Civil Engineering, Indian Institute of Technology, Kharagpur, India 721302 (corresponding author). E-mail: bhargab@civil.iitkgp.ernet.in

${ }^{3}$ Professor, Dept. of Civil Engineering and Geodesy, Darmstadt Univ. of Technology, Petersenstr. 30, 64287 Darmstadt, Germany. E-mail: boltze@ verkehr.tu-darmstadt.de

Note. This manuscript was submitted on August 4, 2011; approved on February 13, 2012; published online on February 16, 2012. Discussion period open until March 1, 2013; separate discussions must be submitted for individual papers. This paper is part of the Journal of Transportation Engineering, Vol. 138, No. 10, October 1, 2012. (C) ASCE, ISSN 0733-947X/ 2012/10-1274-1281/\$25.00.
1980; Geok and Perl 1988; Martins and Pato 1998; Shrivastava and Dhingra 2001; Shrivastava and O'Mahony 2006, 2009; Li and Quadrifoglio 2010). However, there is little information available regarding the planning of rural feeder services in developing countries. Also, adequate emphasis has not been given to the indirect costs to users resulting from hard factors (e.g., walking distance and waiting time) and soft factors (e.g., crowding inside vehicles) of feeder service. In general, planning of feeder service has been carried out considering only the direct cost (or fare) to users and the operational viability of the service. Poor quality of transportation services is a major concern in developing countries such as India. It is necessary to consider both direct and indirect costs to users in the planning of rural feeder services. A case study is presented in this paper for the planning of feeder service in India with due consideration to direct and indirect costs to rural populations and the operational viability of the service. Direct and indirect costs to users are expressed in terms of a comprehensive measure called generalized cost (GC). GC is developed on the basis of the willingness to pay (WTP) of rural commuters with respect to various attributes of rural feeder service. The travel demands likely to be generated from different villages are expected to be low, and therefore a demand-responsive feeder service may be beneficial in a rural context. However, the scope of the present work is limited to the planning of a rural feeder service with a fixed-route, fixed-schedule form of operation. Also, the restructuring of existing bus routes and relocation of bus stops are not included within the scope of the present work.

A feeder route aims to serve rural populations located in the catchments of a bus stop. Therefore, one end (i.e., the bus stop) of the route is fixed, but the other end could be any of the villages located in the catchments of the bus stop. A key issue affecting both user costs and operational viability is the starting point of the route at the village end. The other issues are selection of vehicle type, service headway, and fares. Two types of vehicle (called Trekker and Tempo) that are generally used in rural India are considered as 
alternative feeder vehicles. Travel behavior analysis provides necessary inputs for the planning process and is instrumental in the estimation of travel demands to be served by the feeder service and associated user costs with respect to a feeder route, vehicle type, and fares. Das et al. (2009) investigated the WTP of rural users with respect to various attributes of a feeder service to bus stops. An area of approximately $200 \mathrm{~km}^{2}$ in the state of West Bengal, India, was taken as a case study. The study area is bounded by national highway (NH) in the eastern side, major district roads (MDRs) on the northern and western sides, and the Subarnarekha River on the southern side. Presently, the study area is served by 12 bus stops located on the NH and MDRs. However, the roads within the study area are currently not served by any feeder system. In the present work, planning of rural feeder service is demonstrated with reference to the same study area. Because the study area is the same, a travel behavior database and analysis reported by Das (2008) and Das et al. (2009) are also used advantageously for the estimation of travel demands and user costs.

\section{Methodology}

The basic objective of providing feeder service is to bring benefits to rural commuters. Therefore, it is aimed at maximizing user benefits through optimal selection of route, type of vehicle, headway of service, and fare. The operational viability of service is another key aspect duly considered in this process.

The selection of route is an important consideration because the route description affects user demand, operational viability, and user costs. The carrying capacity, fixed costs, and operating costs are different for two types of feeder vehicle. Accordingly, service characteristics like headway, fare, and operational viability are also affected by the selection of the feeder vehicle type. The methodology followed for maximizing user benefits through optimal selection of route, type of vehicle, headway of service, and fare is summarized in Fig. 1 and explained by the following steps.

\section{Step 0: Develop Input Database}

The input database includes the road network, vehicle characteristics, cutoff revenue (CR), journey speed, minimum layover time, user costs, travel demand, and measure of effectiveness (MOE). All these inputs are described below.

The road network indicating the connectivity between a bus stop and villages in the influence area of the bus stop is a basic input. The road network is used to develop alternative feeder routes and evaluate them to identify the optimal feeder route for a bus stop catchment. The road network in the influence area of each bus stop catchment is a spanning tree that has been developed under the rural road development program (Sikdar 2002).

Vehicle capacity and minimum required revenue (or CR) are vehicle-specific attributes that influence user costs and operational viability. Two types of feeder vehicle are investigated. They are called Trekker and Tempo. Journey speed and layover time affect the minimum number of vehicles required for meeting demand. Travel behavior analysis provides a basis for estimating not only demand to be served by a feeder system but also user costs or user benefits. Travel demand affects service characteristics and operational viability.

Through the selection of optimal variables an attempt may be made to minimize user costs or maximize user benefits. Alternatively, an attempt may be made

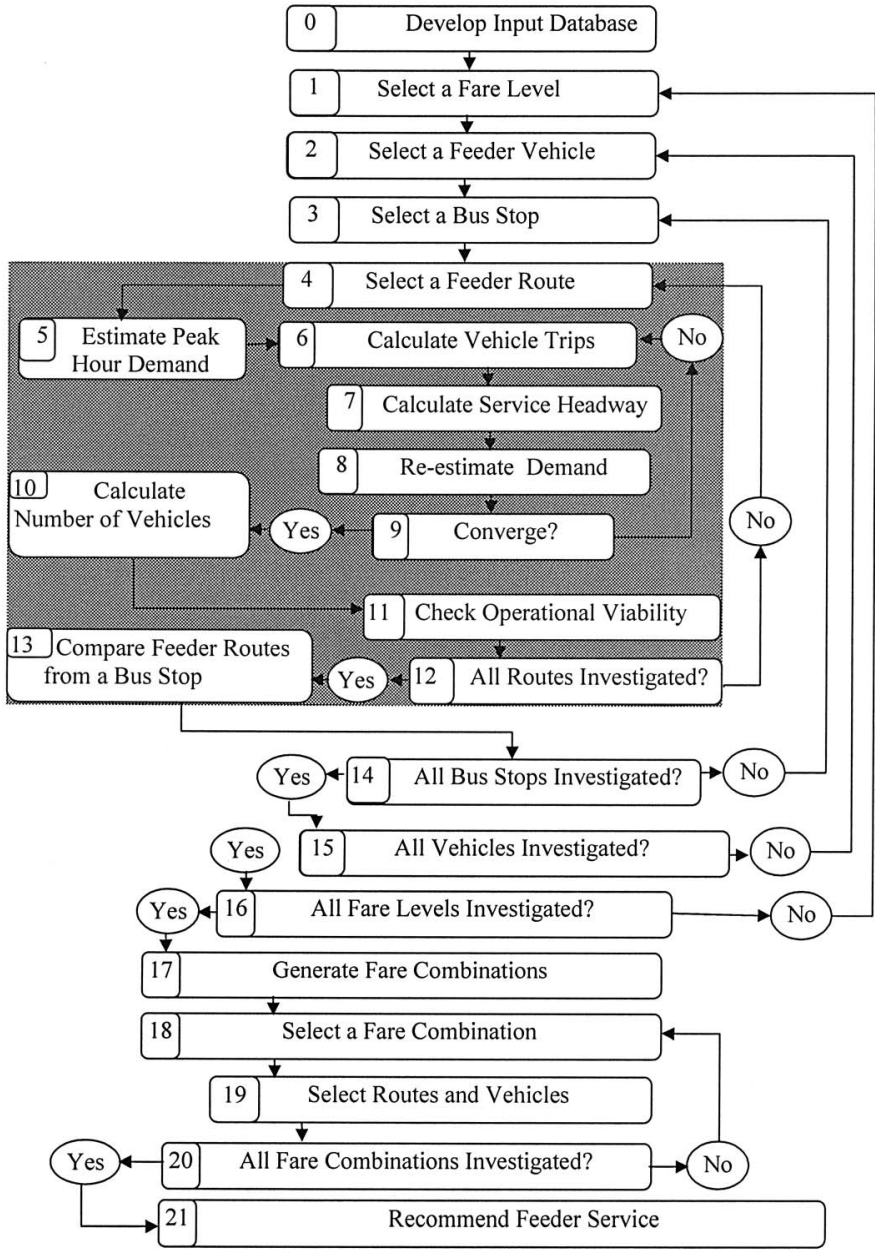

Fig. 1. Selection of optimal feeder route, vehicle type, and fare

to maximize passenger-kilometer served by the feeder service. The measure of effectiveness (MOE) reflects the policy variable, such as user costs or passengerkilometer served, that is optimized in the process of feeder service planning.

Step 1: $\quad$ Select Fare Level

Different fare levels are investigated. Consider a fare level for investigation.

Step 2: $\quad$ Select a Feeder Vehicle

Two types of feeder vehicle are considered. Consider a feeder vehicle type for investigation.

Step 3: Select a Bus Stop

The study area is served by 12 bus stops. Consider a bus stop for investigation.

Step 4: $\quad$ Select a Feeder Route

Several villages are located in the influence area of each bus stop. A feeder route will have one of these villages at one end and a bus stop at the other end. Generate all possible feeder routes with respect to the bus stop by considering each of the villages in turn to represent the other end of the feeder routes. Select a feeder route for investigation.

Theoretically, the villages in the influence area of a bus stop catchment can be served by more than one feeder route. However, as the demand in rural area is generally low and villages are scattered throughout a large geographical area, multiple feeder routes for a bus stop 
catchment are unlikely to be viable and are, therefore, not investigated in the present work. Rather, an attempt is made to identify the most preferred feeder route, if any, that is operationally viable and optimize the selected MOE.

Step 5: Estimate Peak Hour Demand

Initially, the service headway is not known. Therefore, all trips from villages to bus stops are assumed to be made by feeder service. Accordingly, daily demand for the busiest link is estimated. Peak period demand on the busiest link is also estimated using the observed temporal variation of demand.

Step 6: Calculate Vehicle Trips

On the basis of the peak hour directional demand and vehicle capacity, the number of vehicle trips required to serve the peak hour demand is calculated.

Step 7: Calculate Service Headway

Using the required hourly vehicle trips, calculate the service headway. The average waiting time for commuters is taken to be half the headway of service.

Step 8: Reestimate Demand

Demands from different villages to be served by the feeder service are reestimated using a logit model and with inputs such as average waiting time (taken from Step 7), walking distance (according to the description of feeder route in Step 4), and fare (as per Step 1).

Step 9: Check for Convergence

Check the difference between the reestimated demand in Step 8 and the demand used in Step 6 or 7. If the difference is within an acceptable limit, then proceed to Step 10, otherwise go to Step 6.

Step 10: Calculate Number of Vehicles

The round trip time required for a vehicle is calculated using route length, journey speed, and minimum layover time. On the basis of the round trip time, the number of vehicles required to maintain the service headway (Step 7) is calculated.

Step 11: Check Operational Viability

The total daily revenue earned by the route is calculated considering both directions of travel and daily demand. Assuming that this revenue will be distributed equally among all vehicles, the average daily revenue earned per vehicle is calculated. A route is considered viable if the revenue eanred per vehicle is at least equal to the $\mathrm{CR}$. If a route is viable, then passenger served, passenger-km served, user costs, number of vehicles, and other variables are calculated.

Step 12: Check If All Possible Routes Are Investigated

If all possible feeder routes from the bus stop under consideration are investigated, then proceed to Step 13. Otherwise, go to Step 4.

Step 13: Compare Feeder Routes from a Bus Stop

Among all feeder routes investigated (Step 4) from a bus stop, only the viable feeder routes (Step 11) are identified. If there is more than one viable route, then the route that optimizes the MOE is selected. The selected route is the best viable route from a bus stop serving its catchment considering a certain vehicle type and a given fare level.

Step 14: Check If All Bus Stops Are Investigated

If all bus stops are investigated, then proceed to Step 15. Otherwise, go to Step 3.
Step 15: Check If All Vehicle Types Are Investigated If all vehicle types are investigated, then proceed to Step 16. Otherwise, go to Step 2.

Step 16: Check If All Fare Levels Are Investigated If all fare levels are investigated, then proceed to Step 17. Otherwise, go to Step 1.

Step 17: Generate Fare Combinations

Steps 4 to 14 generate the best viable routes, if any, from all bus stops considering a particular vehicle type and a fare level. Step 15 and 16 ensure the generation of such best viable routes considering all vehicle types and fare levels.

For each vehicle type, all fare levels that indicate at least one viable feeder route with savings in user costs are taken. Considering different vehicle types and all fare levels, possible fare combinations are generated for further investigation.

Step 18: Select a Fare Combination

A fare combination includes one fare level for Trekker and another fare level for Tempo.

Step 19: Select Feeder Routes and Vehicles

For a selected fare combination, there is a choice to select either Trekker or Tempo with given fare levels. The selected route must be operationally viable. Now, for each bus stop influence area, the alternative that will optimize the MOE is selected. The same vehicle type may not be selected for all routes. Also, some bus stop catchments may not be served by feeder service if the operation is not viable with the selected vehicle type and fare level. Finally, the MOEs are calculated for each selected feeder routes in the study area.

Step 20: Check If All Fare Combinations Are Investigated If all fare combinations are investigated, then proceed to Step 21. Otherwise, go to Step 18.

Step 21: Recommend Feeder Service

Among all fare combinations, the one indicating the optimum value of the MOE for all the selected feeder routes in the study area is recommended.

\section{Input Database}

The input database includes road network, vehicle characteristics, $\mathrm{CR}$, journey speed and minimum layover time, user costs and demand model, present travel demand from villages, and MOE. Various inputs used to develop the database are described below.

\section{Road Network}

The rural road development program aimed at providing single allweather road connectivity to villages in rural India. Accordingly, the road network developed for connecting villages to bus stops is essentially a spanning tree. The road network considered for the planning of rural feeder service is the same as that developed under a rural road development program. The database includes the length of each link and connecting nodes (i.e., village or bus stop). The road network considered in the present work is shown in Fig. 2. Some salient features of the bus stops surrounding the study area are given in Table 1 . In a developing country like India, walking is the most common form of travel for a distance of up to 1 to $2 \mathrm{~km}$ (Iles 2005). Therefore, villages that are located within $2 \mathrm{~km}$ from bus stops are not considered for the planning of feeder service. 


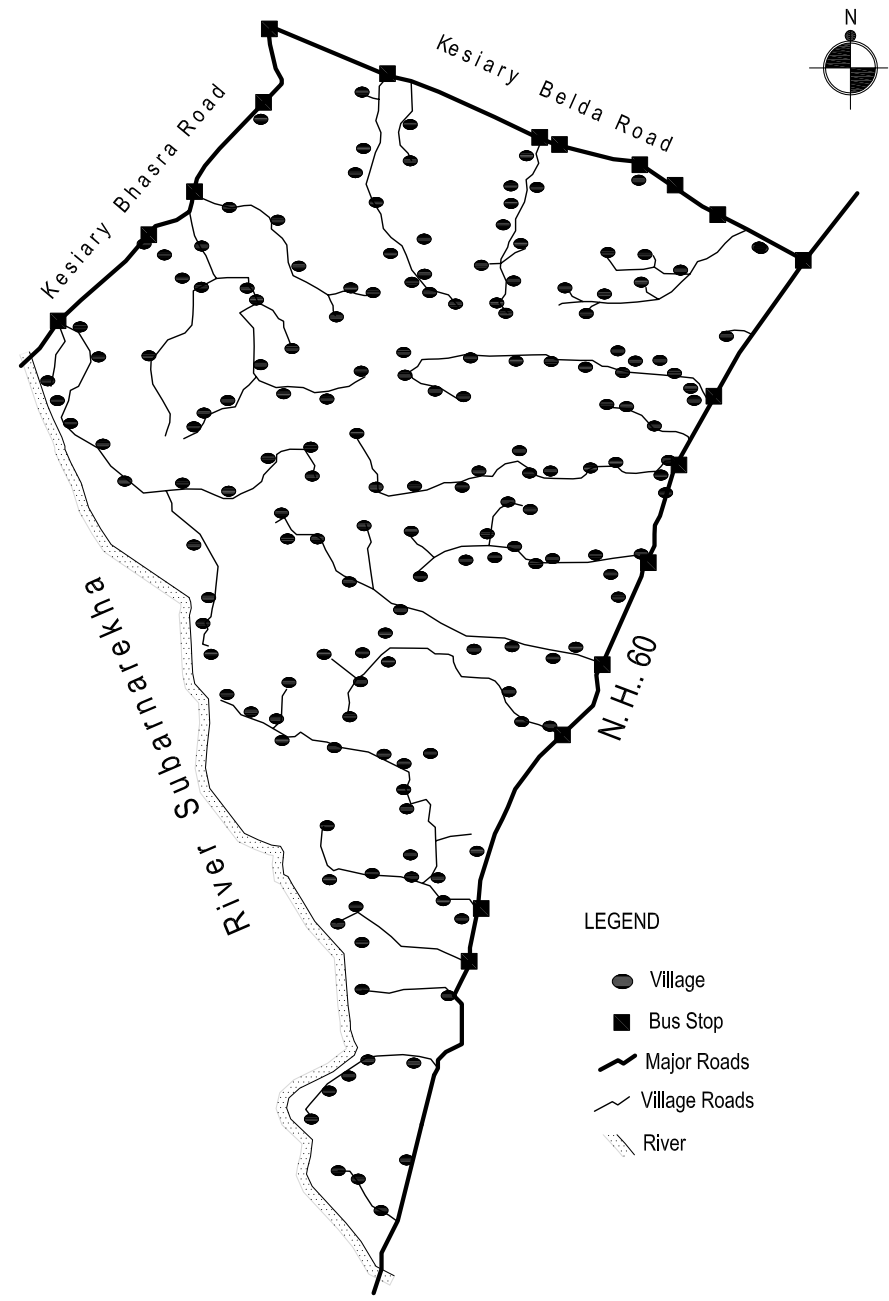

Fig. 2. Road network for planning of rural feeder service

\section{Vehicle Characteristics and Cutoff Revenue}

Two types of vehicle are considered: Tempo, with a carrying capacity of 6 persons, and Trekker, with a carrying capacity of 10 persons. Both capital cost and operating cost are low for these types of vehicle, and they are used widely as paratransit in rural India.

The cutoff revenue is a vital input for judging the operational viability of feeder service. It is considered the minimum revenue required to cover fixed costs and running costs of a vehicle along with a minimum profit to the operator. The fixed costs of vehicle include capital repayment (equitable monthly installment),

Table 1. Summary of Bus Stops and Their Influence Areas

\begin{tabular}{lccc}
\hline Bus stop & Number of villages & Population & Road length $(\mathrm{km})$ \\
\hline Bhasra & 12 & 11,162 & 12.3 \\
Daihara & 6 & 3,151 & 7.2 \\
Dantan & 15 & 9,541 & 14.2 \\
Kalabani & 11 & 5,590 & 8.3 \\
Khokra & 14 & 8,695 & 15.3 \\
Kukai & 8 & 4,188 & 5.5 \\
Monaharpur & 7 & 5,937 & 9.0 \\
Nachipur & 5 & 2,406 & 5.2 \\
Panchyar & 7 & 3,529 & 5.6 \\
Salajpur & 12 & 5,773 & 12.8 \\
Sarisa & 7 & 2,700 & 5.0 \\
Syamalpur & 9 & 2,849 & 6.3 \\
Total & 126 & 74,401 & 120.3 \\
\hline
\end{tabular}

insurance, road tax, permit, and crew cost. Costs associated with fuel, lubricant, tires, and maintenance fall under running cost.

The CR required per day per vehicle is estimated to meet the fixed costs, running costs, and minimum profit for operator. Required CR per day in Indian rupees (INR) are given in Eqs. (1) and (2).

$$
\begin{aligned}
& \mathrm{CR}_{(\text {Trekker })}=247+2.8^{*} d+P \\
& \mathrm{CR}_{(\text {Tempo })}=199+1.5^{*} d+P
\end{aligned}
$$

where, $\mathrm{CR}_{i}$ is the required CR per day in INR for vehicle type $i, d$ is the distance traveled per vehicle per day in kilometers, and $P$ is the minimum profit for the operator per day in INR. In the present work, the profit for operator is taken to be INR 3,000/month per vehicle.

\section{Journey Speed and Minimum Layover Time}

Journey speed and minimum layover time are inputs required for the calculation of round trip time and number of vehicles required to maintain the headway. The journey speed of feeder vehicles in rural areas is considered to be low due to frequent stoppage within a short distance of travel. In the present work, journey speed is taken to be $20 \mathrm{~km}$ per hour and the minimum layover time is taken to be $10 \mathrm{~min}$ at each end.

\section{Travel Behavior Analysis}

For the planning of a rural feeder service, it is necessary to estimate the demand likely to be shifted to the feeder service and the resulting benefits to users. Travel behavior analysis was required to fulfill these two requirements. User costs and demand models, used as inputs for the present work, are obtained as per Das (2008) and Das et al. (2009). The details of model estimation and WTP calculation are omitted here as the focus of the paper is on the planning of a rural feeder service. However, a brief background of demand models and GC equations follows in the context of the present paper.

A stated choice survey instrument was designed considering various attributes and levels of hypothetical feeder service. Rural commuters were asked to state their choice among various feeder service alternatives. Users were also asked to state their choice considering feeder service alternatives and the present mode (i.e., bicycle or motorcycle). Initially (say, Stage I), the choice responses obtained with respect to feeder service alternatives only were analyzed by developing various econometric models such as multinomial logit (MNL) and random parameter logit (RPL). Stage I analysis was useful for estimating trip maker WTP values with respect to various attributes and levels of hypothetical feeder service. Stage I analysis also indicated that the WTP values with respect to various feeder service attributes were different for bicycle and motorcycle users. The WTP values estimated in Stage I analysis were used advantageously for the next stage analysis (say, Stage II) of the stated choice database that included feeder service alternatives and the present mode (i.e., bicycle or motorcycle). In Stage II, separate econometric models were developed for bicycle and motorcycle users on the basis of the observations made in Stage I. Stage II models were used for demand modeling purposes and were also instrumental for estimating WTP with respect to attributes of present modes (i.e., bicycle and motorcycle).

The utility equations as obtained from RPL models in Stage II analysis for bicycle and motorcycle users with respect to a fixedschedule form of operation of rural feeder service are given in 
Eqs. (3) and (4). These utility equations are used to estimate the likely shift of demand to feeder service. Traveling as standee is not a viable option for feeder vehicles considered in the present work. However, often in rural India such vehicles are found to carry more passengers than the seat capacity specified by vehicle manufacturer(s). Traveling under such conditions causes additional discomfort to passengers and the travel was described as "congested seating" in a stated choice experiment. When vehicles carry passenger only up to the seat capacity specified by the manufacturer, the travel was described as "comfortable seating." These are reflected through various coefficient estimates of $\alpha_{c}$ and $\alpha_{m}$ :

$$
\begin{gathered}
U_{c}=\mathrm{ASC}_{c}+\alpha_{c}{ }^{*} D-0.477 \mathrm{AWD}-0.068 \mathrm{WT}-0.009 \mathrm{TC} \\
U_{m}=\mathrm{ASC}_{m}+\alpha_{m}{ }^{*} D-0.675 \mathrm{AWD}-0.085 \mathrm{WT}-0.005 \mathrm{TC}
\end{gathered}
$$

where $U_{c}=$ utility of travel for present bicycle users; $U_{m}=$ utility of travel for present motorcycle users; $\mathrm{ASC}_{c}=0$ for bicycle, 2.411 for Tempo, and 4.206 for Trekker; $\mathrm{ASC}_{m}=0$ for motorcycle, 3.086 for Tempo, and 4.827 for Trekker; $\alpha_{c}=0.900$ if the travel is under conditions of conditions of comfortable seating in a feeder vehicle, 0.594 if the travel is under conditions of congested seating in a feeder vehicle, -0.551 if the travel is by bicycle; $\alpha_{m}=-0.463$ if the travel is under conditions of comfortable seating in a feeder vehicle, -0.787 if the travel is under conditions of congested seating in a feeder vehicle, -0.468 if the travel is by motorcycle; $D=$ total distance traveled (in kilometers) using either an existing mode or a feeder vehicle; AWD = access walking distance (in kilometers) to the nearest feeder stop; WT $=$ waiting time (in minutes) for the next feeder vehicle; $\mathrm{TC}=$ total direct cost of travel in paise (1 INR = 100 paise).

The WTP values of bicycle and motorcycle users with respect to various attributes/levels are calculated using the coefficient estimates given in Eqs. (3) and (4). These WTP values are used to develop the GC equations as given in Eqs. (5) and (6):

$$
\begin{aligned}
\mathrm{GC}_{c} & =\beta_{c}{ }^{*} D+53.0^{*} \mathrm{AWD}+7.56^{*} \mathrm{WT}+\mathrm{TC} \\
\mathrm{GC}_{m} & =\beta_{m}{ }^{*} D+134.9^{*} \mathrm{AWD}+17.0^{*} \mathrm{WT}+\mathrm{TC}
\end{aligned}
$$

where $\mathrm{GC}_{c}=$ generalized cost for present bicycle users in paise; $\mathrm{GC}_{m}=$ generalized cost for present motorcycle users in paise; $\beta_{c}=0$ if travel is under conditions of comfortable seating in a vehicle, 32.7 if travel is under conditions of congested seating in a vehicle, and 155.0 if travel is by bicycle; $\beta_{m}=0$ if travel is under conditions of comfortable seating in a vehicle, 67.7 if travel is under conditions of congested seating in a vehicle, and 1 if travel is by motorcycle.

\section{Travel Demand}

Travel demand between each village and the nearest bus stop is a key input for the work. It was necessary to model bus-stop-bound travel demand generated from various villages in the study area and capture the temporal variation of demand. Accordingly, trip rates for different categories of household are analyzed. Households are classified into three categories: cultivator, daily labor, and service/ business on the basis of the occupation of the head of household. Trip rates are also estimated separately for revenue-generating and non-revenue-generating trips. Non-revenue-generating trips are further classified into two categories: educational trips (i.e., trips made for educational purposes only) and household trips (i.e., trips made for social, recreational, and household purposes).

The trip rates for revenue-generating trips are estimated per working member of the household, while educational and
Table 2. Household Income and Trip Rates

\begin{tabular}{lccc}
\hline $\begin{array}{l}\text { Household } \\
\text { category }\end{array}$ & $\begin{array}{c}\text { Household } \\
\text { monthly } \\
\text { income (INR) }\end{array}$ & $\begin{array}{c}\text { Revenue-generating } \\
\text { trip per day per } \\
\text { working population }\end{array}$ & $\begin{array}{c}\text { Education trip } \\
\text { per day per } \\
\text { household }\end{array}$ \\
\hline Cultivator & 3,070 & 0.019 & 0.201 \\
Daily laborer & 1,715 & 0.047 & 0.095 \\
Service/business & 5,140 & 0.318 & 0.229 \\
\hline
\end{tabular}

household trips are estimated per household. This is done in order to make the estimated trip rates compatible with the secondary data. The trip rates for revenue-generating trips are estimated on the basis of data collected from 1,691 working persons representing different categories of household. The educational and household trip rates are estimated on the basis of data collected from 998 households. Average household income of each category is given in Table 2. The modeled trip rates with respect to revenue-generating trips and educational trips are also summarized in Table 2.

The trip rate for revenue-generating trips is the highest for service and business category followed by daily laborers and cultivators. Service and business populations are expected to travel more frequently than laborers/cultivators. However, the observed trip rate even for service and business population does not indicate daily travel to a bus stop. Because of a lack of transport connectivity and other reasons, a part of the service population stays in town and visits home (in village) approximately once a week. The revenue-generating trip rates also indicate that very few daily laborers go out of their village for work. Cultivators also travel to bus stops only occasionally to purchase agricultural goods such as pesticides, seeds, and fertilizer.

Educational trip rates as reported in Table 2 are primarily for higher-education purposes. The educational trip rates may be related to the income of household category. Higher-income households place more emphasis on higher education. Daily laborer households do not usually send their children away for higher education. Accordingly, a low trip rate is estimated for this category.

Socioeconomic characteristics of household- and village-level attributes are used to model household trip rates. A regression model with household income, family size, and bus stop distance as explanatory variables is developed as shown in Eq. (7):

$$
\begin{aligned}
\mathrm{HT}_{i j}= & 0.0001+0.00003 \times \mathrm{HI}_{i j}+0.041 \times \mathrm{FS}_{i j}-0.036 \\
& \times \log \left(\mathrm{BSD}_{i}\right)
\end{aligned}
$$

where $\mathrm{HT}_{i j}=$ trip rate (i.e., trip per day) for household category $j$ in village $i, \mathrm{HI}_{i j}=$ household monthly income (in INR) of category $j$ in village $i, \mathrm{FS}_{i j}=$ family size of category $j$ in village $i$, and $\mathrm{BSD}_{i}=$ distance to the nearest bus stop (in kilometers) from village $i$.

The $t$-statistics of all parameter estimates in Eq. (7) except for the constant are found to be statistically significant with a confidence level of more than $95 \%$. Therefore, the model is reestimated by neglecting the constant. The $t$-statistics of the coefficients of $\mathrm{HI}_{i j}, \mathrm{FS}_{i j}$, and $\log \left(\mathrm{BSD}_{i}\right)$ for the reestimated model are calculated as $18.4,20.2$, and 3.8 , respectively. The $R^{2}$ value of the reestimated model is 0.693 . Therefore, the household trip production per day for category $j$ household in village $i$ is expressed as given in Eq. (8):

$\mathrm{HT}_{i j}=0.00003 \times \mathrm{HI}_{i j}+0.04 \times \mathrm{FS}_{i j}-0.033 \times \log \left(\mathrm{BSD}_{i}\right)$

The signs of the coefficient estimates of the model are logical. The positive sign of coefficient estimates of household income and family size indicate that the number of trips increases with an increase in household income and family size. The negative sign 


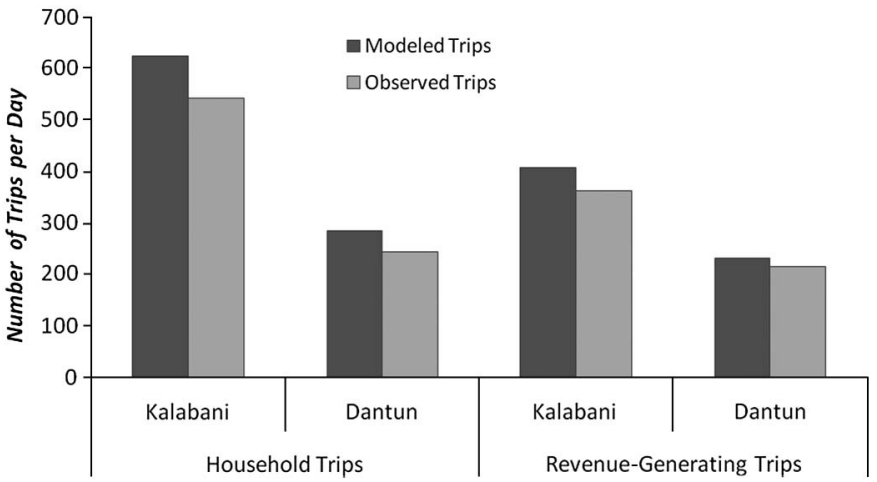

Fig. 3. Comparison of modeled and observed trips

of the coefficient of bus stop distance from village indicates a decrease in the number of trips with an increase in the distance from a bus stop.

The total trips generated from village $i$ to the nearest bus stop is given in Eq. (9):

$$
T_{i}=\sum_{j=1}^{3} \mathrm{ET}_{j} \mathrm{HH}_{i j}+\sum_{j=1}^{3} \mathrm{HT}_{i j} \mathrm{HH}_{i j}+\sum_{j=1}^{3} \mathrm{RT}_{j} P_{i j}
$$

where $T_{i}=$ total daily trips to nearest bus stop from village $i$, $\mathrm{HH}_{i j}=$ number of households in village $i$ under household category $j, \mathrm{ET}_{j}=$ educational trip rate for household category $j, \mathrm{HT}_{i j}=$ household trip rate in village $i$ for household category $j, \mathrm{RT}_{j}=$ revenue-generating trip rate for household category $j$, and $P_{i j}=$ number of workers in village $i$ under worker category $j$.

Before accepting the modeled trip rates, it was necessary to validate them. Validation of trip rates was done by counting the number of trip makers going to bus stops and recording their trip purpose. Two bus stops, Dantun and Kalabani, were selected for this purpose. A comparison of modeled and observed revenuegenerating trips and household trips is shown in Fig. 3. Educational trips could not be validated because during validation survey, educational institutes were closed due to summer vacation. It may be observed from Fig. 3 that the modeled trips are generally in agreement with the observed trips. Therefore, the modeled trip rates are accepted for estimating trip generation from villages to bus stops.

The primary survey indicated that $83 \%$ of outbound trips (i.e., to bus stops) were made during 5:30 a.m. to 12:30 p.m. On the other hand, around $81 \%$ of inbound trips (i.e., from bus stops) were made during the period from 12:30 p.m. to 7:30 p.m. Inbound and outbound trips between 7:30 p.m. and 5:30 a.m. were negligible. Therefore, the span of operation of feeder service is considered to be between 5:30 a.m. and 7:30 p.m. Also, trips during morning hours (i.e., between 5:30 a.m. to 12:30 p.m.) and evening hours (i.e., 12:30 p.m. to 7:30 p.m.) are assumed to be uniformly distributed during different hours.

\section{Measure of Effectiveness}

It is necessary to consider an appropriate MOE while selecting feeder routes and vehicles. An attempt is made to optimize the MOE in the process of identifying operationally viable feeder routes. The MOE primarily represents the objective of providing feeder service in a quantitative manner. The selection of $\mathrm{MOE}$ is, therefore, a policy matter. Different objective functions or quantitative measures that have been used in transportation studies include, for example, generalized cost (Silman et al. 1974;
Duff-Riddell and Bester 2005), generalized time (Lampkin and Saalmans 1967; Dubois et al. 1979; Mandl 1980; Ceder and Wilson 1986), consumer surplus (Hasselström 1981), number of trips (VanNes et al. 1988), and service coverage (Spasovic et al. 1994; Ramirez and Seneviratne 1996). In the present work, selection of feeder routes and vehicles is demonstrated considering two alternative MOEs: generalized cost (GC) and passenger-kilometer served. A reduction in $\mathrm{GC}$ is a rational measure of user benefits. Therefore, with GC as MOE, the routes and vehicle types are selected to minimize the GC or maximize the GC savings. On the other hand, with passenger-kilometer as MOE, the routes and vehicle types are selected to maximize the passenger-kilometer served by the feeder service.

\section{Results from the Case Study}

In what follows, the selection of optimal feeder route, vehicle, headway, and fare for two different MOEs, i.e., GC saving and passenger-kilometer served, is discussed considering a fixed-route, fixed-schedule form of operation.

\section{Fare Combinations}

The fare directly affects patronage and revenue. Therefore, selection of feeder route and vehicle is also affected by the fare. In the present work, a fare range of INR 0.50 per kilometer to INR 2.0 per kilometer is considered. However, only practical fare levels represented in multiples of INR 0.25 are considered for investigation. Fare levels of INR $0.50 / \mathrm{km}$ and INR $0.75 / \mathrm{km}$ did not produce any viable feeder route during initial investigations. On the other hand, fare levels beyond INR $1.25 / \mathrm{km}$ did not produce any savings in GC. Therefore, INR $1.00 / \mathrm{km}$ and INR $1.25 / \mathrm{km}$ are the only two practical fare levels identified in the present study that produced viable feeder route(s) with GC savings. Accordingly, fare combinations as given in Table 3 are investigated.

\section{Feeder Service with GC as MOE}

Routes of different bus stop catchments are selected optimizing the GC of trip makers as per the methodology shown in Fig. 1. The details of viable routes and vehicles selected for different bus stop catchments are reported in Table 4. The table includes the name of the bus stop, the number of vehicles, and the type of vehicle required to serve the catchment. The length of the feeder route with the number of passengers served, passenger-kilometer served, GC savings, and revenue surplus (i.e., revenue earned in excess of CR) are also given in the table. With fare combination FC-I, no viable route is obtained for any bus stop influence area. Under FC-II, three viable routes are identified. The number of viable routes is found to increase under FC-III and FC-IV. A summary of feeder service under different fare combinations is reported in Table 5. As shown in Table 5, GC savings are highest under FC-IV. Therefore, FC-IV and its corresponding routes and vehicle are recommended. FC-IV

Table 3. Selected Fare Combinations

\begin{tabular}{lcc}
\hline Fare combination & Fare of Trekker & Fare of Tempo \\
\hline FC-I & 1.00 & 1.00 \\
FC-II & 1.00 & 1.25 \\
FC-III & 1.25 & 1.00 \\
FC-IV & 1.25 & 1.25 \\
\hline
\end{tabular}

Note: Fares are in INR per kilometer. 
Table 4. Details of Feeder Service with GC as MOE

\begin{tabular}{|c|c|c|c|c|c|c|}
\hline Fare & Bus stop & $\begin{array}{l}\text { Vehicle } \\
\text { type }\end{array}$ & $\begin{array}{l}\text { Route length } \\
(\mathrm{km})\end{array}$ & $\begin{array}{l}\text { Passenger-km } \\
\text { served per day }\end{array}$ & $\begin{array}{l}\text { Number of passengers } \\
\text { served per day }\end{array}$ & $\begin{array}{l}\text { Total GC savings } \\
\text { (INR/day) }\end{array}$ \\
\hline \multirow[t]{3}{*}{ FC-II } & Bhasra & Tempo & 8 & 4,982 & 757 & 1,231 \\
\hline & Daihara & Tempo & 5.9 & 1,180 & 212 & 215 \\
\hline & Dantun & Tempo & 7.9 & 3,107 & 483 & 753 \\
\hline \multirow[t]{7}{*}{ FC-III } & Bhasra & Trekker & 9.7 & 5,430 & 771 & 1,188 \\
\hline & Daihara & Trekker & 6.6 & 1,277 & 218 & 165 \\
\hline & Dantun & Trekker & 8.9 & 3,273 & 493 & 714 \\
\hline & Kalabani & Trekker & 6.3 & 1,802 & 372 & 337 \\
\hline & Manoharpur & Trekker & 5.8 & 2,293 & 513 & 425 \\
\hline & Salajpur & Trekker & 6.3 & 2,290 & 485 & 482 \\
\hline & Syamalpur & Trekker & 3.2 & 642 & 208 & 9 \\
\hline \multirow[t]{7}{*}{ FC-IV } & Bhasra & Tempo & 8 & 4,982 & 757 & 1,231 \\
\hline & Daihara & Tempo & 5.9 & 1,180 & 212 & 215 \\
\hline & Dantun & Tempo & 7.9 & 3,106 & 483 & 753 \\
\hline & Kalabani & Trekker & 6.3 & 1,802 & 372 & 337 \\
\hline & Manoharpur & Trekker & 5.8 & 2,293 & 513 & 425 \\
\hline & Salajpur & Trekker & 6.3 & 2,290 & 485 & 482 \\
\hline & Syamalpur & Trekker & 3.2 & 642 & 208 & 9 \\
\hline
\end{tabular}

Table 5. Summary of Feeder Service with GC as MOE

\begin{tabular}{|c|c|c|c|c|c|c|c|}
\hline Fare & $\begin{array}{l}\text { Route length } \\
\qquad(\mathrm{km})\end{array}$ & Passenger-km & $\begin{array}{l}\text { Number of } \\
\text { Trekkers }\end{array}$ & $\begin{array}{l}\text { Number of } \\
\text { Tempos }\end{array}$ & $\begin{array}{l}\text { Total number } \\
\text { of vehicles }\end{array}$ & $\begin{array}{c}\text { Number of } \\
\text { passengers served }\end{array}$ & $\begin{array}{l}\text { GC savings } \\
\text { in INR/day }\end{array}$ \\
\hline FC-II & 21.8 & 9,269 & 0 & 33 & 33 & 1,453 & 2,198 \\
\hline FC-III & 46.8 & 17,007 & 43 & 0 & 43 & 3,060 & 3,320 \\
\hline FC-IV & 43.8 & 16,296 & 19 & 33 & 52 & 3,031 & 3,451 \\
\hline
\end{tabular}

Table 6. Details of Feeder Service with Passenger-Kilometer as MOE

\begin{tabular}{|c|c|c|c|c|c|c|}
\hline Fare & Bus stop & $\begin{array}{l}\text { Vehicle } \\
\text { type }\end{array}$ & $\begin{array}{l}\text { Route length } \\
(\mathrm{km})\end{array}$ & $\begin{array}{l}\text { Passenger-km } \\
\text { served per day }\end{array}$ & $\begin{array}{l}\text { Number of passengers } \\
\text { served per day }\end{array}$ & $\begin{array}{c}\text { GC savings } \\
\text { (INR/day) }\end{array}$ \\
\hline \multirow[t]{3}{*}{ FC-II } & Bhasra & Tempo & 9.0 & 5,280 & 757 & 1,276 \\
\hline & Daihara & Tempo & 5.9 & 1,180 & 212 & 214 \\
\hline & Dantun & Tempo & 7.9 & 3,107 & 483 & 753 \\
\hline \multirow[t]{7}{*}{ FC-III } & Bhasra & Trekker & 9.7 & 5,430 & 771 & 1,188 \\
\hline & Daihara & Trekker & 6.6 & 1,277 & 218 & 165 \\
\hline & Dantun & Trekker & 8.9 & 3,273 & 493 & 714 \\
\hline & Kalabani & Trekker & 6.3 & 1,802 & 372 & 337 \\
\hline & Manoharpur & Trekker & 5.8 & 2,293 & 513 & 425 \\
\hline & Salajpur & Trekker & 6.3 & 2,290 & 485 & 482 \\
\hline & Syamalpur & Trekker & 3.2 & 642 & 208 & 9 \\
\hline \multirow[t]{7}{*}{ FC-IV } & Bhasra & Trekker & 9.7 & 5,430 & 771 & 1,188 \\
\hline & Daihara & Trekker & 6.6 & 1,277 & 218 & 165 \\
\hline & Dantun & Trekker & 8.9 & 3,273 & 493 & 714 \\
\hline & Kalabani & Trekker & 6.3 & 1,802 & 372 & 337 \\
\hline & Manoharpur & Trekker & 5.8 & 2,293 & 513 & 425 \\
\hline & Salajpur & Trekker & 6.3 & 2,290 & 485 & 482 \\
\hline & Syamalpur & Trekker & 3.2 & 642 & 208 & 9 \\
\hline
\end{tabular}

Table 7. Summary of Feeder Service in Passenger-Kilometer as MOE

\begin{tabular}{lcccccc}
\hline Fare & $\begin{array}{c}\text { Route length } \\
(\mathrm{km})\end{array}$ & Passenger-km & $\begin{array}{c}\text { Number of } \\
\text { Trekkers }\end{array}$ & $\begin{array}{c}\text { Number of } \\
\text { Tempos }\end{array}$ & $\begin{array}{c}\text { Total number of } \\
\text { vehicles }\end{array}$ & $\begin{array}{c}\text { Number of } \\
\text { passengers served }\end{array}$ \\
\hline FC-II & 22.8 & 9,566 & 0 & 34 & 34 & 1,452 \\
FC-III & 46.8 & 17,007 & 43 & 0 & 43 & 3,060 \\
FC-IV & 46.8 & 17,007 & 43 & 0 & 43 & 3,060 \\
\hline
\end{tabular}

is expected to offer viable feeder service covering parts of the seven bus stop influence areas. It may be observed from Table 5 that the fare combination (i.e., FC-IV) producing the highest GC savings do not maximize the route length and passenger-kilometer. This indicates that the selection of routes and vehicle is likely to be different if passenger-kilometer is taken as the MOE. 


\section{Feeder Routes and Vehicle with Passenger-Kilometer as MOE}

Feeder routes and vehicles are also selected for all bus stop catchments taking passenger-kilometer served as the MOE. The results are shown in Tables 6 and 7. With fare combination FC-I, no viable route is obtained for any bus stop influence area. As shown in Table 7, both FC-IV and FC-III serve maximum passengerkilometers. Other attributes of the selected routes in both fare combinations have the same value. This is because in both fare combinations only Trekker is the selected as a feeder vehicle and the fare level for Trekker is same in FC-III and FC-IV. In addition, Table 7 shows that the fare combinations producing the maximum passengerkilometers also maximize the route length and GC savings.

\section{Conclusion}

The majority of rural populations are from economically weaker sections with negligible private vehicle ownership; therefore, the public transport system is an important consideration in the context of rural India. Although buses generally serve the majority of higher-order roads, access to bus stops from villages using appropriate feeder service is largely a missing component. A case study is presented for the planning of feeder service in rural India with a fixed-route, fixed-schedule form of operation. Traditionally, the planning of rural feeder service has been carried out without due consideration to indirect costs associated with hard factors (e.g., walking distance and waiting time) and soft factors (e.g., crowding inside vehicles) of the service. The present work demonstrates an approach to the planning of rural feeder service considering direct and indirect costs to users and the operational viability of the service. Direct and indirect costs are expressed in terms of a comprehensive measure called generalized. The work demonstrates the effect of catchment characteristics (i.e., number of villages, size of villages, and spatial separation represented by road network connecting villages to bus stops) on feeder service attributes (i.e., type of vehicle, route, service headway, and fare). It is also shown that the planning of feeder service could be instrumental in bringing benefits to rural communities. In the present work, benefits resulting from feeder service is expressed in terms of a reduction in GC. The work also demonstrates the role of measure of effectiveness in the context of planning rural feeder service. The results presented in the paper are case specific, but the methodology can be applied to the planning of feeder services in other rural regions.

\section{Acknowledgments}

The work presented in this paper is carried out with support from Deutscher Akademischer Austausch Dienst (DAAD) and Alexander von Humboldt Stiftung. The authors express their sincere thanks to Deutscher Akademischer Austausch Dienst (DAAD) and Alexander von Humboldt Stiftung for their support towards international exchange and research.

\section{References}

Ceder, A., and Wilson, N. H. M. (1986). "Bus network design." Transp. Res. B, 20(4), 331-344.

Das, S. S. (2008). "Planning of rural feeder service to bus stop." Doctoral thesis, IIT Kharagpur, India.

Das, S. S., Maitra, B., and Boltze, M. (2009). "Valuing travel attributes of rural feeder service to bus stop: A comparison of different logit model specifications." J. Transp. Eng., 135(6), 330-337.

Dubois, D., Bel, G., and Llibre, M. (1979). "A set of methods in transportation network synthesis and analysis." J. Oper. Res. Soc., 30(9), 797-808.

Duff-Riddell, W. R., and Bester, C. J. (2005). "Network modeling approach to transit network design." J. Urban Plann. Dev., 131(2), 87-97.

Geok, K., and Perl, J. (1988). "Optimization of feeder bus routes and bus stop spacing." J. Transp. Eng., 114(3), 341-354.

Hasselström, D. (1981). "Public transportation planning: A mathematical programming approach." Doctoral thesis, Univ. of Gothenburg, Sweden

Iles, R. (2005). Public Transport in Developing Countries, Elsevier, Amsterdam.

Lampkin, W., and Saalmans, P. D. (1967). "The design of routes, service frequencies and schedules for a municipal bus undertaking: A case study." Oper. Res. Q., 18(4), 375-397.

Li, X., and Quadrifoglio, L. (2010). "Feeder transit services: Choosing between fixed and demand responsive policy." Transp. Res. C Emerg. Technol., 18(5), 770-780.

Mandl, C. E. (1980). "Evaluation and optimization of urban public transportation networks." Eur. J. Oper. Res., 5(6), 396-404.

Martins, C. L., and Pato, M. V. (1998). "Search strategies for the feeder bus network design problem." Eur. J. Oper. Res., 106(2-3), 425-440.

Ramirez, A. I., and Seneviratne, P. N. (1996). "Transit route design applications using goegraphic information systems." Transportation Research Record 1557, Transportation Research Board, Washington, DC, $10-14$.

Shrivastava, P., and Dhingra, S. L. (2001). "Development of feeder routes for suburban railway stations using heuristic approach.” J. Transp. Eng., 127(4), 334-341.

Shrivastava, P., and O'Mahony, M. (2006). "A model for development of optimized feeder routes and coordinated schedules: A genetic algorithms approach." Transport Policy, 13(5), 413-425.

Shrivastava, P., and O’Mahony, M. (2009). "Modeling an integrated public transportation system: A case study in Dublin, Ireland." Eur. Transport Trasporti Europei, 41, 28-46.

Sikdar, P. K. (2002). "Pradhan Mantri Gram Sadak Yojana, for the people, by the people." Indian Highways, 30(6), 59-68.

Silman, L. A., Brazily, Z., and Passy, U. (1974). "Planning the route system for urban buses." Comput. Oper. Res., 1(2), 201-211.

Spasovic, L. N., Boile, M. P., and Bladikas, A. K. (1994). "Bus transit service coverage for maximum profit and social welfare." Transportation Research Record 1451, Transportation Research Board, Washington, DC, 12-22.

VanNes, R., Hamerslag, R., and Immer, B. H. (1988). "Design of public transport networks." Transportation Research Record 1202, Transportation Research Board, Washington, DC, 74-83.

Wirasinghe, S. C. (1980). "Nearly optimal parameters for a rail feeder bus system on a rectangular grid." Transp. Res. A Policy Practice, 14A(1), $33-40$. 